\title{
STABILITY ANALYSIS OF A SINGLE-PHASE VOLTAGE SOURCE INVERTER
}

\author{
A. El-Sabbe, H. A. Yassin, S. S. Shokralla and M. S. Zaky \\ Department of Electrical Engineering, Faculty of Engineering, Shebin El-Kom \\ Minoufiya University, Egypt
}

\begin{abstract}
This paper presents the analysis of a single-phase voltage source inverter with a second order filter. The differential equations describing the system behavior in the different modes of operation are given. A general state space model of the voltage source inverter is first derived. A linearized small signal dynamic model is then developed from the system general model using perturbation and small signal approximation. Root locus analysis presents the study of the system parameters, which affect the system stability. A feedback output voltage control loop is inserted into the system with proportional-integral (PI) controller. Liapunov stability method is performed to determine the condition of the modulation index for stability. The simulation results are given and proved to yield good agreement when compared with the experimental results.

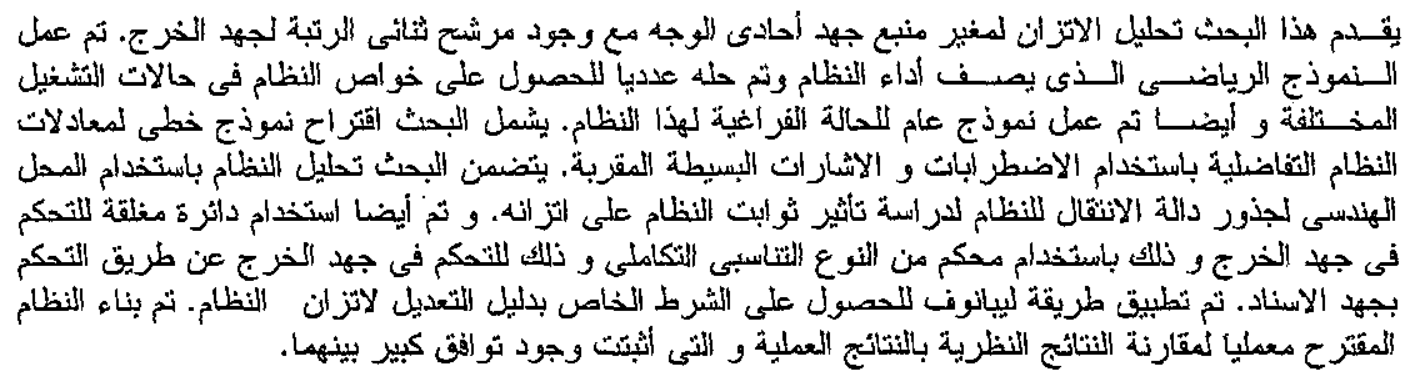

\section{INTRODUCTION}

The conventional voltage source inverter (VSI) is used in many distinct industrial and commercial applications. The most important of them are uninterruptible power supply (UPS) and ac motor drives.

The conversion from dc/ac power is carried out by employing a combination of a pulse width modulation (PWM) scheme and a second order filter at the output of the inverter: The output voltage of the voltage source inverter is required to be sinusoidal with minimum total harmonic distortion.

One way of achieving a pure sinusoidal load voltage is obtained by using a sinusoidal pulse width modulation (SPWM) scheme. According to this technique the load voltage is compared with a reference sinusoidal voltage waveform and the difference in amplitude is used to control the modulating signal in the control drive circuit of the power inverter [1,2].

To make these techniques acceptable to operate with nonlinear loads, an inner feedback control loop for sensing the current in the capacitor of the load filter is used. An outer voltage feedback loop is also incorporated to ensure that the load voltage is sinusoidal and well regulated. Although the technique results give a sinusoidal current, the power circuit configuration produce a load voltage that is sinusoidal with dc offset, which is not acceptable for UPS applications [3].

A voltage source inverter (VSI) can generate an ac output voltage larger than the $\mathrm{dc}$ input one, depending on the instantaneous duty ratio, which is referred to the boost dc-ac inverter which is different from the classical voltage source inverters that produce an ac output instantaneous voltage always lower than the dc input one. To ensure correct operation of the boost inverter under any working condition, a sliding mode controller is used [4].

Many studies were reported for dc to ac inverters. The analysis and simulation for such systems have been presented in analytical form. No attention has been paid to the stability analysis of power electronic system parameters or factors that affect the system stability [1-9]. 
In this paper, the simulation and experimental studies are obtained for a system which consists of an (R-L) load fed from dc to ac single-phase pulse width modulated inverter using two switches (IGBT's) and a second order filter. The differential equations, which describe the system behavior, are obtained. These differential equations of the system are placed in state-space form. A linearized small signal dynamic model is then developed from the system general model using perturbation and small-signal approximation. Stability analysis is studied using Root-locus plot; also Liapunov method of stability is employed to determine the control law of the modulation index or duty ratio for the system stability. A feedback output voltage loop is incorporated into the system with PI controller to enhance the system stability and ensure that the constant load voltage is pure sinusoidal waveform irrespective of disturbances. The simulation results have been verified experimentally and the results are found to be in a good agreement.

\section{SYSTEM DESCRIPTION}

Figure 1 shows the circuit configuration of a single-phase dc to ac PWM voltage source inverter. The circuit consists of a second order filter and two switches (IGBT's). The generation of gate pulses is accomplished by comparing a saw tooth signal of amplitude $V_{m}$ (modulating signal) with a variable dc voltage $V_{C}$ (control voltage). Changing the amplitude of $\mathrm{dc}$ control voltage varies the ac output voltage of the inverter. The block diagram representation of the single-phase voltage source inverter is shown in Figure 2. The experimental waveforms of the control signals and gate pulses are shown in Figure 3. The system parameters are given in the appendix.

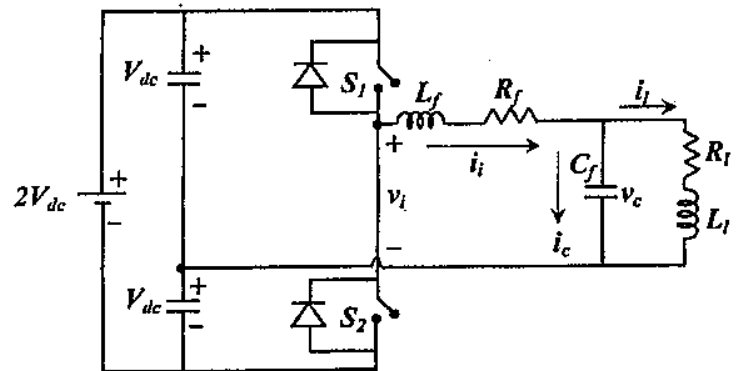

Fig. 1 The circuit configuration of a single- phase voltage source inverter

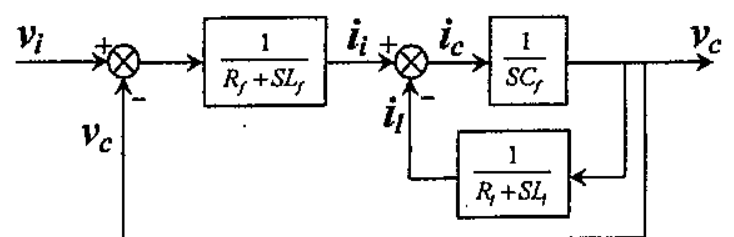

Fig. 2 The block diagram representation for the system

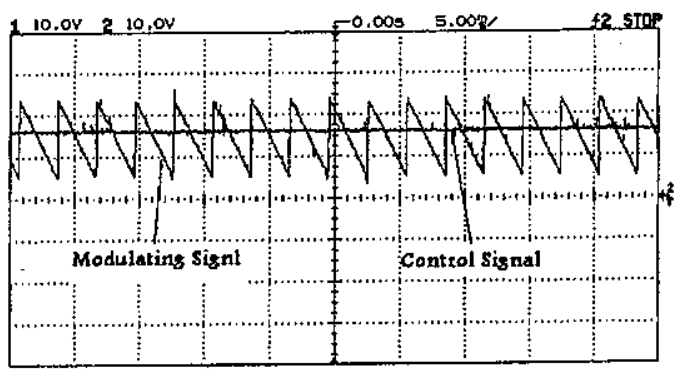

(a) Modulating and Control signal

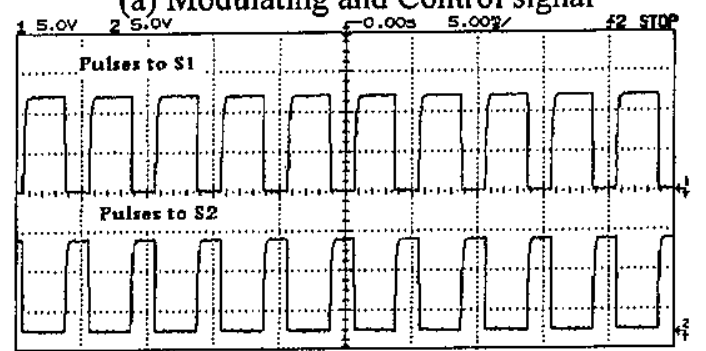

(b) Gate pulses

Fig. 3 Experimental results of the modulating, control signal and the gate pulses.

\section{SYSTEM MODELING AND MODES OF OPERATION}

The system differential equations can be written for the modes of operation as follows:

\section{Mode 1: -}

The equivalent circuit of this mode is shown in Figure 4. In this mode, the switch $S_{1}$ is turned on and the switch $S_{2}$ is turned off. The corresponding differential equations describing this mode are as follows:

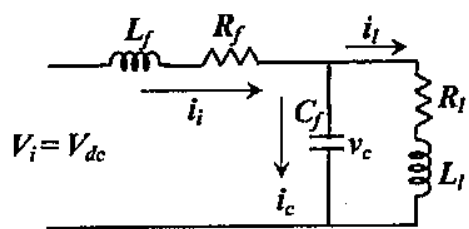

Fig. 4 Equivalent circuit of mode 1

$$
\begin{aligned}
& v_{i}=V_{d c} \\
& v_{i}=R_{f} i_{i}+L_{f} \frac{d i_{i}}{d t}+v_{C} \\
& i_{C}=i_{i}-i_{l} \\
& v_{c}=\frac{1}{C_{f}} \int i_{C} d t=\frac{1}{C_{f}} \int\left(i_{i}-i_{l}\right) d t \\
& v_{C}=R_{l} i_{l}+L_{l} \frac{d i_{l}}{d t}
\end{aligned}
$$

where $R_{f}, L_{f}$ and $C_{f}$ are the filter resistance, inductance and capacitance, respectively, $R_{l}$ and $L_{l}$ are the load resistance and inductance; $v_{i}$ and $i_{i}$ are the inverter output PWM voltage and current, $V_{d c}$ is the dc input voltage, $v_{C}$ is the output voltage, $i_{C}$ is the current in filter capacitor and $i_{l}$ is the load current. 


\section{Mode 2:-}

The equivalent circuit of this mode is shown in Figure 5. In this mode the switch $S_{2}$ is turned on and the switch $S_{1}$ is turned off. The corresponding differential equations describing this mode are as follows:

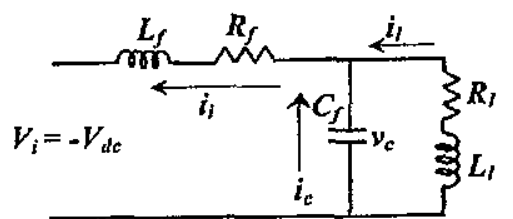

Fig. 5 Equivalent circuit of mode 2

$$
\begin{aligned}
& v_{i}=-V_{d c} \\
& v_{i}=R_{f} i_{i}+L_{f} \frac{d i_{i}}{d t}+v_{C} \\
& i_{C}=i_{i}-i_{l} \\
& v_{C}=\frac{1}{C_{f}} \int i_{C} d t=\frac{1}{C_{f}} \int\left(i_{i}-i_{l}\right) d t \\
& v_{C}=R_{l} i_{l}+L_{l} \frac{d i_{l}}{d t}
\end{aligned}
$$

The system differential equations can be written in a general state space form as follows:

$$
\left.\frac{d}{d t}\left[\begin{array}{l}
i_{i}(t) \\
i(t) \\
v_{c}(t)
\end{array}\right]=\left[\begin{array}{ccc}
-\frac{R_{f}}{L_{f}} & 0 & -\frac{1}{L_{f}} \\
0 & -\frac{R_{f}}{L_{i}} & \frac{1}{L_{f}} \\
\frac{1}{C_{f}} & -\frac{1}{C_{f}} & 0
\end{array}\right] \begin{array}{c}
i_{i}(t) \\
i_{f}(t) \\
v_{C}(t)
\end{array}\right]+\left[\begin{array}{c}
\frac{V_{d c}}{L_{f}}\left(2 S_{l}-1\right) \\
0 \\
0 \\
\end{array}\right]
$$

Where $\left(S_{1}=1\right)$ when $S_{1}$ is on and $\left(S_{1}=0\right)$ when $S_{1}$ is off: Equation (11) is discontinuous due to the presence of the switching function. An averaged time-continuous model of the voltage source inverter can be obtained for Equation (11) by assuming that the inverter switching frequency, $f_{s}$, is much higher than the frequency of the modulating signal. Consequently, the discontinuous switching function $S_{1}$ can be replaced by its time dependent duty ratio $d_{l}(t)$ [3]:

$$
d_{1}(t)=\frac{1}{2}\left(\frac{V_{m}}{V_{c}}+1\right)
$$

Then, the system state-space averaged continuous model can be obtained by the following equation:

$$
\left.\frac{d}{d t}\left[\begin{array}{c}
i_{i}(t) \\
i_{l}(t) \\
v_{C}(t)
\end{array}\right]=\left[\begin{array}{ccc}
-\frac{R_{f}}{L_{f}} & 0 & -\frac{1}{L_{f}} \\
0 & -\frac{R_{f}}{L_{f}} & \frac{1}{L_{f}} \\
\frac{1}{C_{f}} & -\frac{1}{C_{f}} & 0
\end{array}\right] \begin{array}{c}
i_{i}(t) \\
i_{l}(t) \\
v_{C}(t)
\end{array}\right]+\left[\begin{array}{c}
\frac{m V_{d c}}{L_{f}} \\
0 \\
0
\end{array}\right]
$$

where the modulating index $m$ is equal to $\frac{V_{m}}{V_{C}}$ :-

\section{STABILITY ANALYSIS.}

The most important problem in linear control systems concerns stability. That is, under what conditions will a system become unstable? If it is unstable, how should we stabilize the system?

The study of system stability occurs at ignoring the filtering resistance $R_{f}$, which has an effect on the stability [3]. With ignoring $R_{f}$, the poles of the system characteristic equation are moves toward the imaginary axis, lowering the stability of the system. In this paper, the effect of the system parameters, which affect the stability, is presented.

\subsection{Linearization Model.}

The system equations of a single-phase voltage source inverter with R-L load given by Eqn. (13) are nonlinear. To develop the dynamic model of the voltage source inverter due to the nonlinearity, the system equations are first linearized around a nominal steady-state operating point. This is carried out using perturbation technique and small signal approximation, which in matrix form is given below:

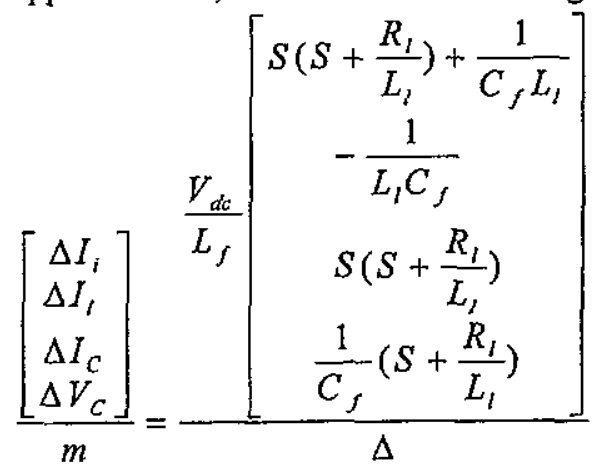

where;

$$
\begin{aligned}
\Delta & =S^{3}+\left(\frac{R_{f}}{L_{f}}+\frac{R_{l}}{L_{l}}\right) S^{2}+\left(\frac{1}{L_{l} C_{f}}+\frac{R_{f} R_{l}}{L_{f} L_{l}}+\frac{1}{L_{f} C_{f}}\right) S \\
& +\left(\frac{R_{f}}{L_{l} L_{f} C_{f}}+\frac{R_{f}}{L_{f} C_{f} L_{l}}\right)
\end{aligned}
$$

and $\Delta I_{i}, \Delta I_{i}, \Delta I_{C}$, and, $\Delta V_{C}$ indicate the incremental changes in the inverter output current, load current, capacitor current and capacitor (load) voltage, respectively, as a result of incremental changes in the duty ratio, and hence the modulation index. Equation (14) shows that, the location of the system poles is dependent on the input dc voltage $\left(V_{d c}\right)$, the system parameters $\left(L_{b}, R_{b}, L_{f}, R_{f}\right.$ and $\left.C_{f}\right)$ and the modulation index, $m$.

\subsection{Root- Locus Analysis}

Figure 6 shows the root locus of the capacitor voltage with respect to the modulation index in the 
existence of $R_{f}$ and when it is ignored. This figure shows that when increasing the loop gain the system stability increases. The system is absolutely stable. The system is -1 relatively stable. There are two complex conjugate roots, so the system exhibits to decayed oscillations.

Figure 7 shows the root locus of the inverter output current with respect to the modulation index in two cases (existence of $R_{f}$ and when it is ignored) where the system is absolutely stable and -1.2 relatively stable. When the loop gain is equal to $F$, the system doesn't exhibit any oscillations and the zeros move to the left hand side of the complex region.

Figure 8 shows the root locus of the capacitor current with respect to the modulation index in case of existence $R_{f}$ and when it is ignored. This figure shows that the system zeros move along the real axis. This has the effect of providing active damping to any oscillations that may take place in the power circuit.

Figure 9 shows the root locus of the load current with respect to the modulation index in case of existence $R_{f}$ and when it is ignored. This figure shows that, the effect of taking $R_{f}$ into consideration is to increase the damping and so its stability.

Figures 6-9 show the effect of changing the filter resistance $R_{f}$ on capacitor voltage, inverter output current, capacitor current and load current. When $R_{f}$ is ignored, the damping coefficient $\xi$ will be zero which means no- damping system of the sustained oscillations. Increasing the filter resistance $R_{f}$ increases the damping coefficient and increases the damping of the system.

Figures 10-13 show the effect of increasing and decreasing the filter capacitance, $C_{f}$, on capacitor voltage, inverter output current, capacitor current and load current. Increasing the filter capacitance increases the damping coefficient of the system and deceases the natural frequency, since $\xi=\frac{R_{f}}{2} \sqrt{\frac{C_{f}}{L_{f}}}, \omega_{n}=\frac{1}{\sqrt{L_{f} C_{f}}}$.

Figures 14-17 show the effect of increasing and decreasing the filter inductance, $L_{f}$, on capacitor voltage, inverter output current, capacitor current and load current. Increasing the filter inductance decreases the damping of the system, where the damping coefficient decreases. The natural frequency of the system decreases with increasing the filter inductance, $L_{f}$.

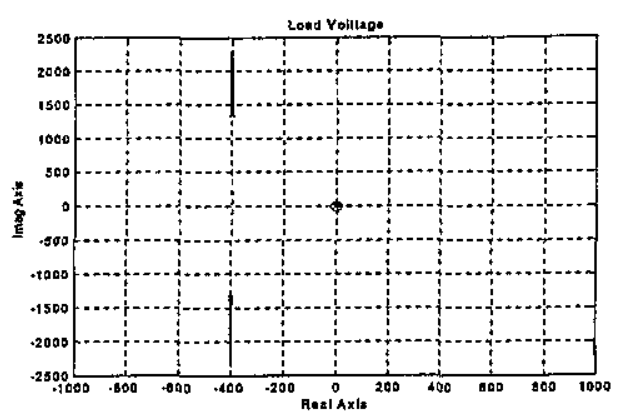

(a) Consider $R_{f}$

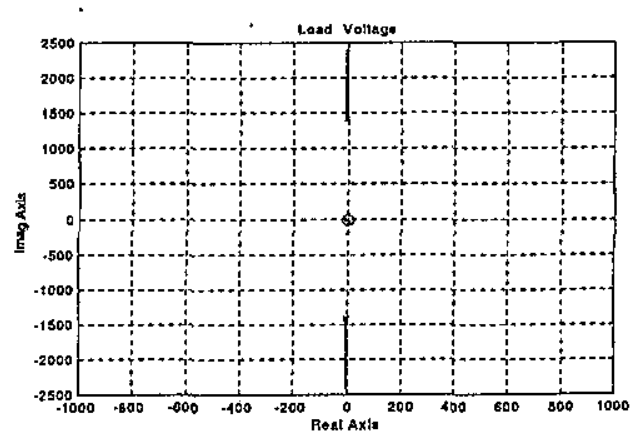

(b) Neglect $R_{f}$

Fig. 6 Root locus of the capacitor (load) voltage

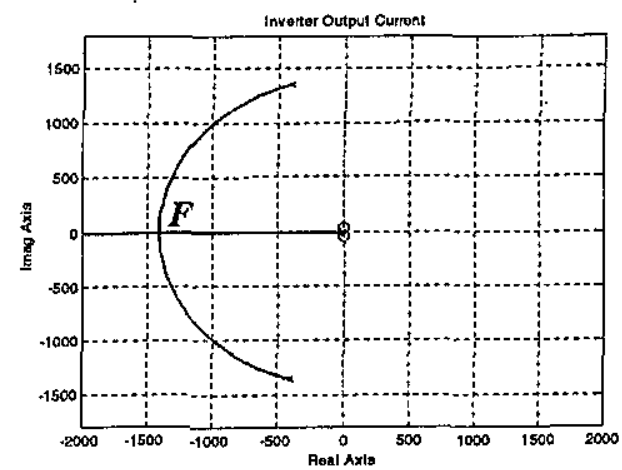

(a) Consider $R_{f}$

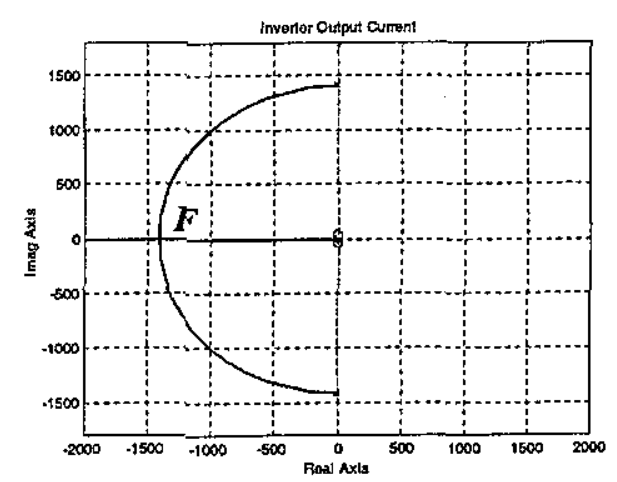

(b) Neglect $R_{f}$

Fig. 7 Root locus of the inverter output current 


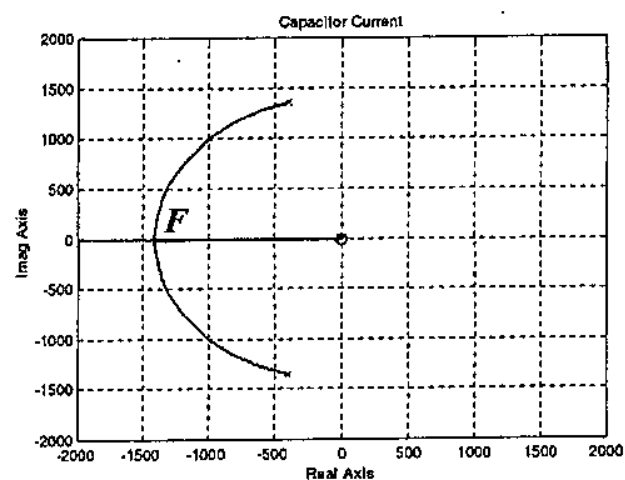

(a) Consider $R_{f}$

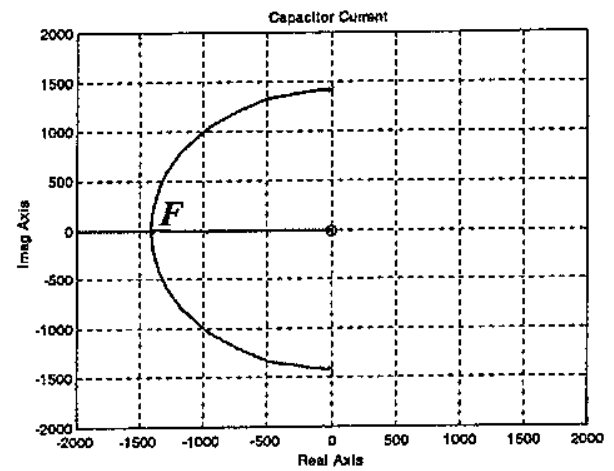

(b) Neglect $R_{f}$

Fig. 8 Root locus of the capacitor Current

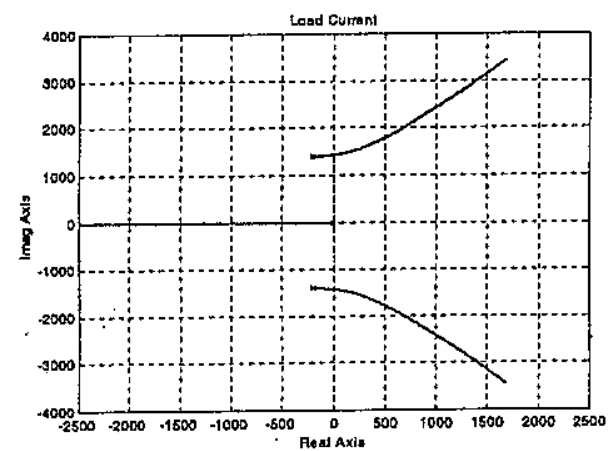

(a) Consider $R_{f}$

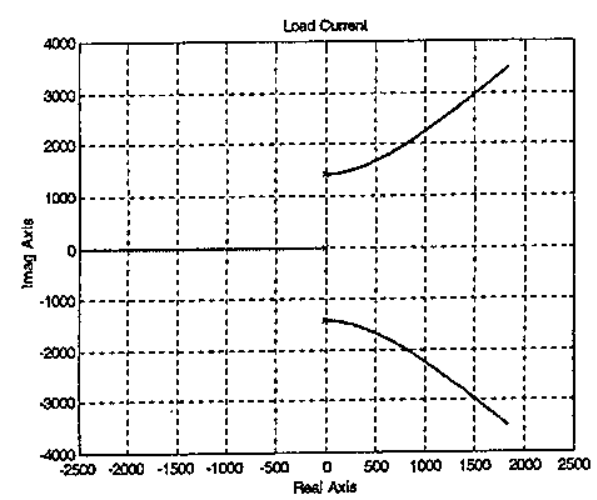

(b) Neglect $R_{f}$

Fig. 9 Root locus of the load Current

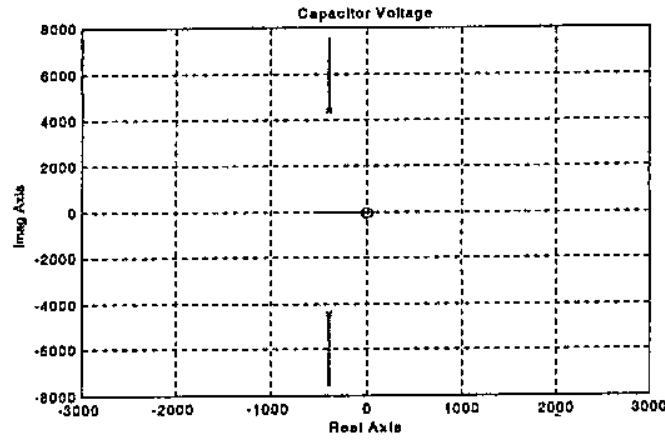

(a) Decrease $C_{f}$

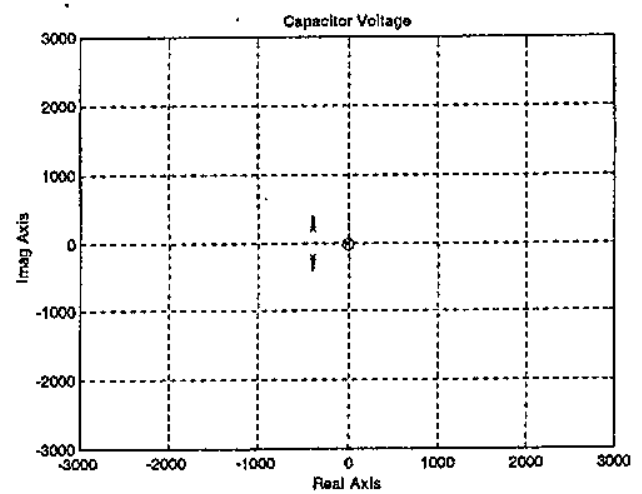

(b) Increase $C_{f}$

Fig. 10 Root locus of the capacitor (load) voltage

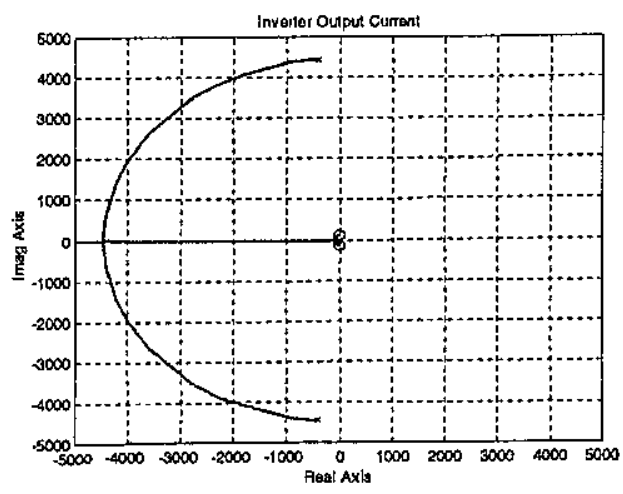

(a) Decrease $C_{f}$

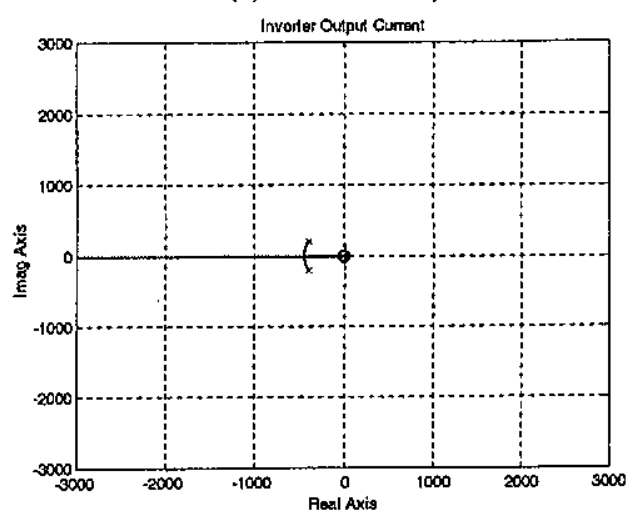

(b) Increase $C_{f}$

Fig. 11 Root locus of the inverter output current 


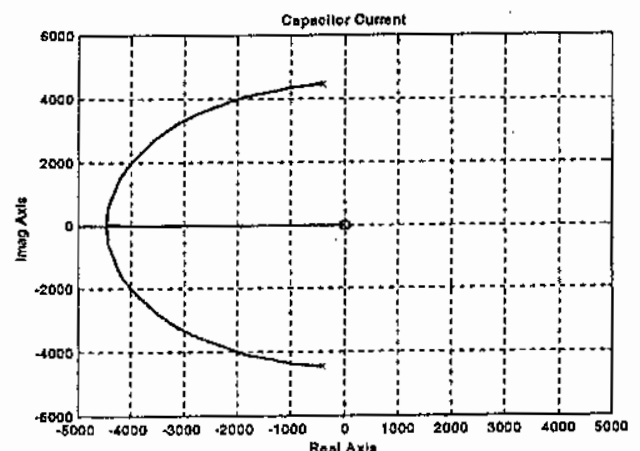

(a) Decrease $C_{f}$

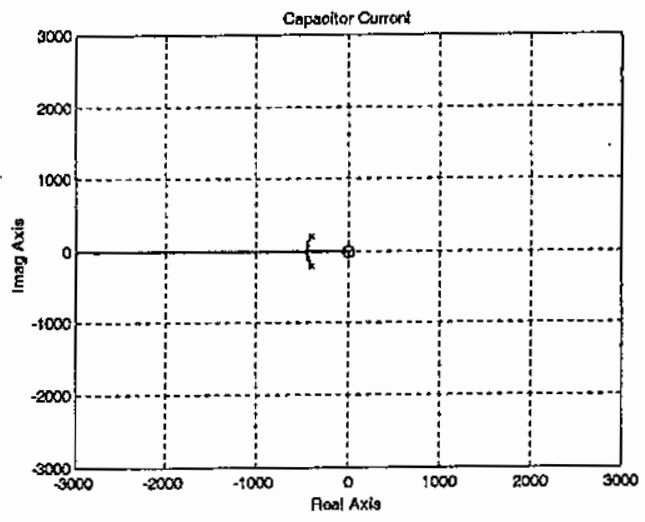

(b) Increase $C_{f}$

Fig. 12 Root locus of the capacitor current

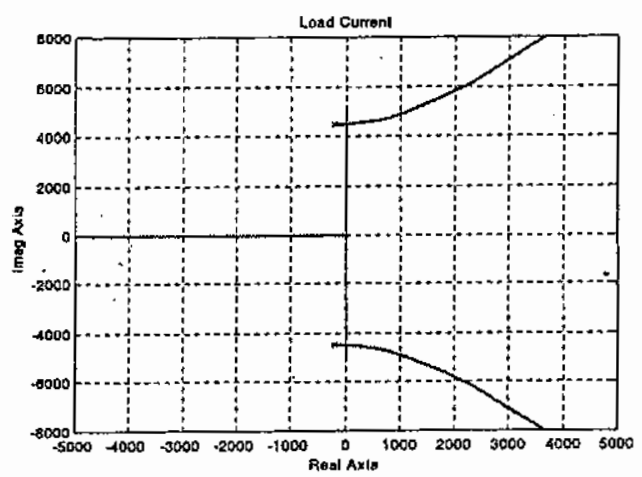

(a) Decrease $C_{f}$

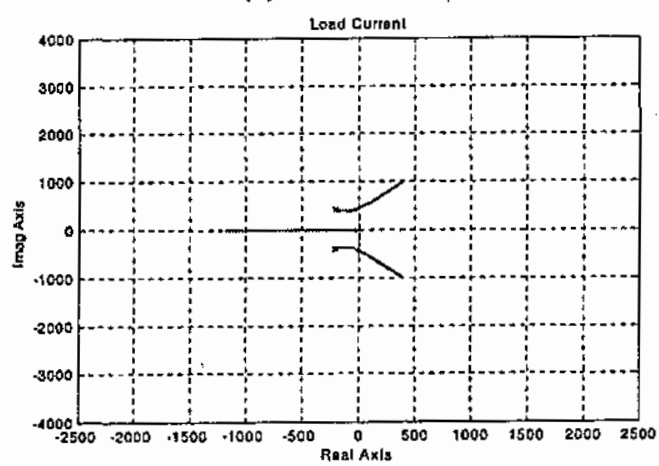

(b) Increase $C_{f}$

Fig. 13 Root locus of the load current

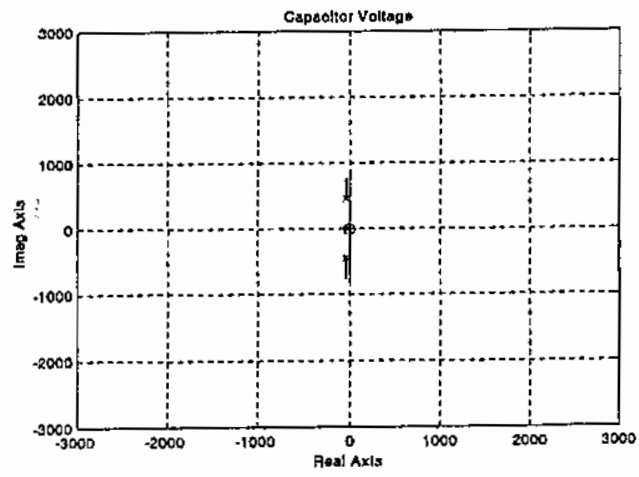

(a) Increase $L_{f}$

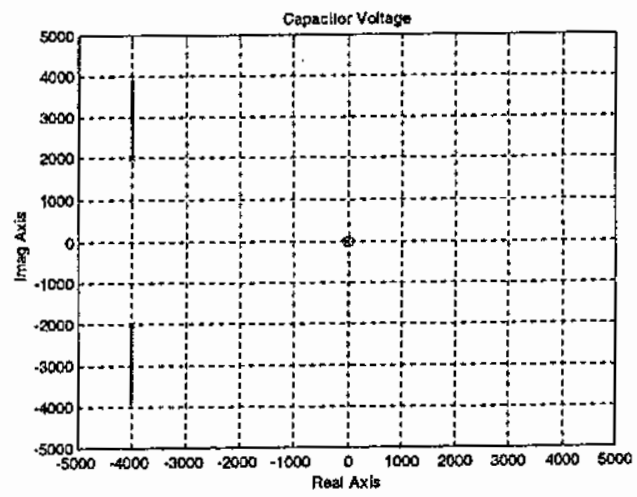

(b) Decrease $L_{f}$

Fig. 14 Root locus of the capacitor voltage

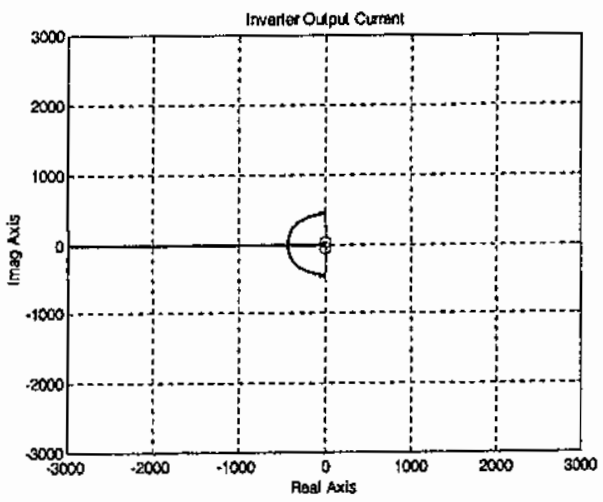

(a) Increase $L_{f}$

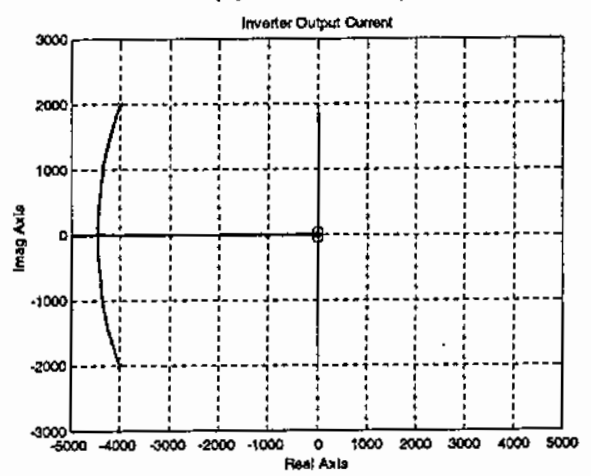

(b) Decrease $L_{f}$

Fig. 15 Root locus of the inverter output current 


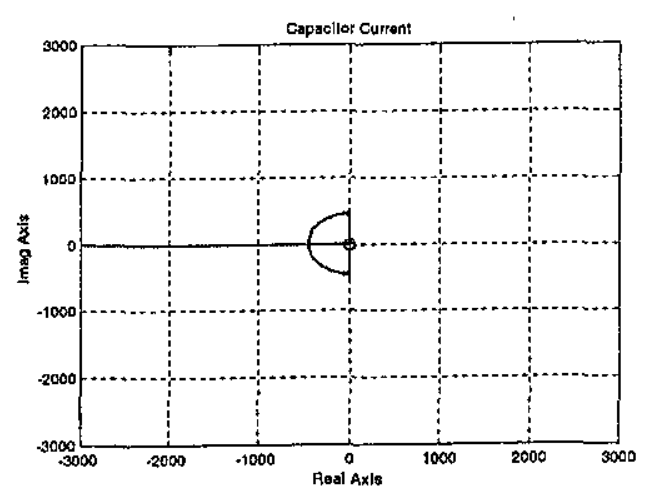

(a) Increase $L_{f}$

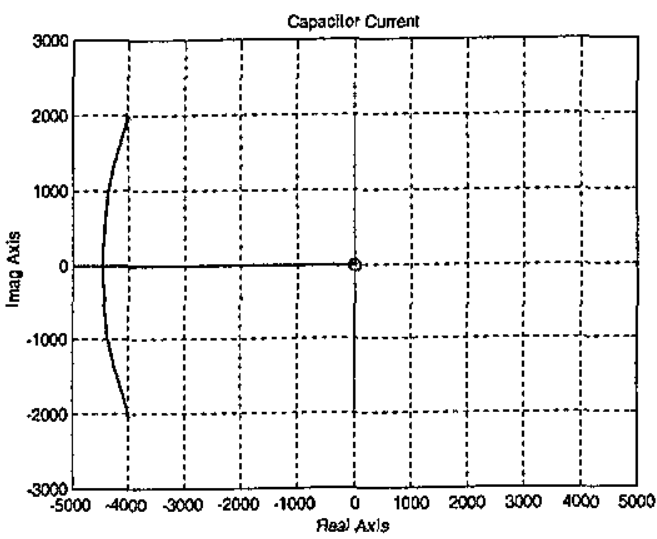

(b) Decrease $L_{f}$

Fig. 16 Root locus of the capacitor current

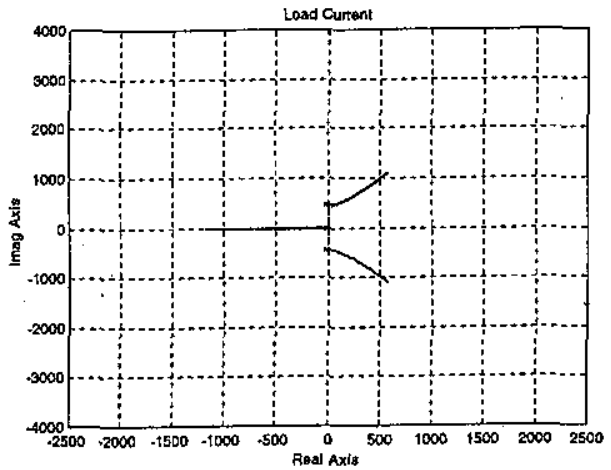

(a) Increase $L_{f}$

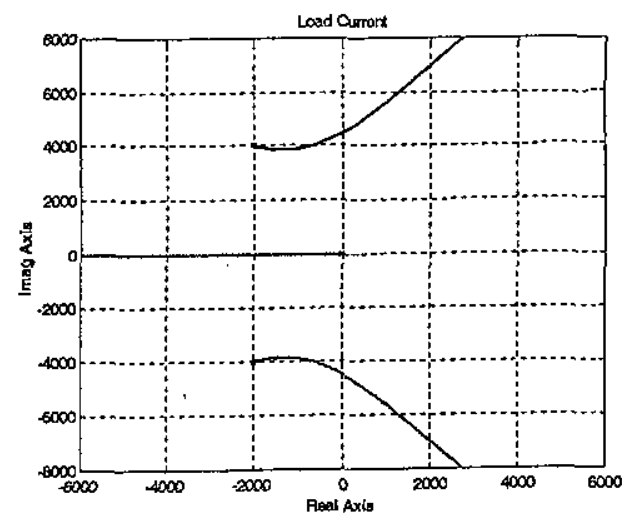

(b) Decrease $L_{f}$

Fig. 17 Root locus of the load current

\subsection{Liapunov Stability Analysis}

If the system is linear and time invariant, many stability criteria are available. Among them are the Nyquist stability criterion, Routh's stability criterion and the Root-locus analysis. If the system is nonlinear, or linear but time varying, then such stability criteria do not apply. Liapunov stability method is the most general method for determining the stability of nonlinear and/or time-varying systems. Let

$$
\begin{gathered}
i_{i}=X_{1}, i_{l}=X_{2}, v_{C}=X_{3} \\
a_{1}=\frac{R_{f}}{L_{f}}, a_{2}=\frac{1}{L_{f}}, b_{1}=\frac{R_{l}}{L_{l}}, b_{2}=\frac{1}{L_{l}}, C=\frac{1}{C_{f}}
\end{gathered}
$$

Then the state equations can be written

$$
\begin{aligned}
& \dot{X}_{1}=-a_{1} X_{1}-a_{2} X_{3}+a_{2} m V_{d c} \\
& \dot{X}_{2}=-b_{1} X_{2}+b_{2} X_{3} \\
& \dot{X}_{3}=C X_{1}-C X_{2}
\end{aligned}
$$

Choose the liapunov function is as follows:

$$
V(X)=\frac{1}{2} \sum_{K=1}^{3} X_{K}^{2}
$$

which has a continuous derivative as,

$$
\begin{aligned}
& \dot{V}(X)=X_{1} \dot{X}_{1}+X_{2} \dot{X}_{2}+X_{3} \dot{X}_{3} \\
& =-a_{1} X_{1}^{2}-b_{1} X_{2}^{2}+\left(C-a_{2}\right) X_{1} X_{3}+\left(b_{2}-C\right) X_{2} X_{3}+a_{2} X_{1} m V_{d c}
\end{aligned}
$$

Using the theorems of the second method of Liapunov, the system is stable when $V(X)$ is positive definite and $\dot{V}(X)$ is negative definite [8]. So the control law of the modulation index $m$ to make $\dot{V}(X)$ negative definite is

$$
\begin{aligned}
& m \leq \frac{1}{a_{2} X_{1} V_{d c}}\left[\left(a_{2}-C\right) X_{1} X_{3}+\left(C-b_{2}\right) X_{2} X_{3}\right] \\
& m \leq \frac{L_{f}}{i_{i} V_{d c}}\left[\left(\frac{1}{L_{f}}-\frac{1}{C_{f}}\right) i_{i} v_{C}+\left(\frac{1}{C_{f}}-\frac{1}{L_{l}}\right) i_{l} v_{C}\right]
\end{aligned}
$$

\section{THE CLOSED LOOP SYSTEM WITH A PI CONTROLLER}

In order to ensure that the voltage source inverter system will produce the constant load voltage, irrespective of disturbances such as variations in the input supply voltage, perturbations in the switching times and the load voltage, a PI controller scheme is used. Also, the PI controller minimizes the steady state error and ensures a fast response system.

Figure 18 shows the block diagram of the closed loop PI voltage controller. Figure 19 shows the root locus plot of the open loop and closed loop voltage source inverter. Without the controller, there is a zero at the origin that makes the system stability decreases with increasing the loop gain. On the other hand, with a PI controller, this zero moves from the origin to 
-0.99 . Note that, the parameters of the PI controller are re-chosen according to the load and system parameters.

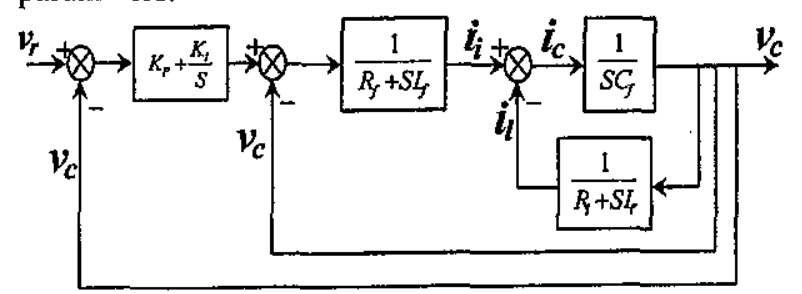

Fig. 18 The closed loop system with PI controller

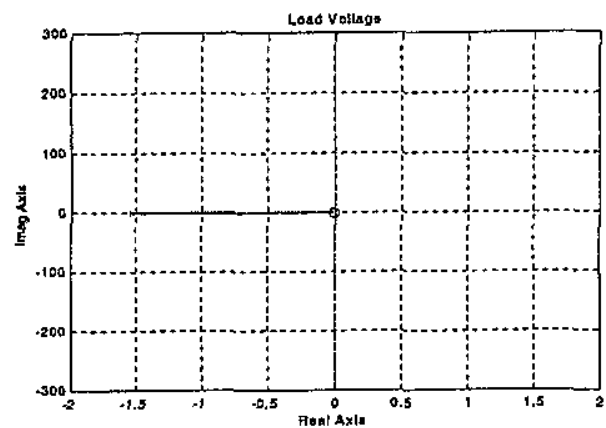

(a) Without Controller

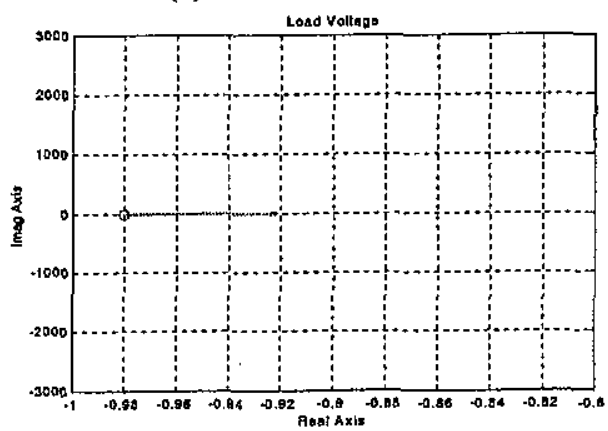

(b) With Controller

Fig. 19 Root locus of the load voltage

\section{SIMULATION AND EXPERIMENTAL RESULTS}

A prototype experimental module of the proposed voltage source inverter shown in Figure 1 was built to verify the simulation and operation of the system. Figure 20 shows the simulation and experimental results for the load voltage and the load current. This figure shows that the load voltage and load current are sinusoidal waveform. As shown, the simulation results have been verified experimentally and the results are found to be in a good agreement.

Figure 21 shows the experimental response of the Ioad voltage and current due to $20 \%$ step change in the reference voltage $\left(V_{r}\right)$ from positive to negative value and from negative to positive value. It is clear that the load voltage follows the desired reference voltage smoothly,

Figure 22 shows the experimental response of the load voltage and current due to $20 \%$ step change in the reference voltage from negative to positive value and from positive to negative value. It is observed that the load voltage follows the desired reference voltage smoothly.
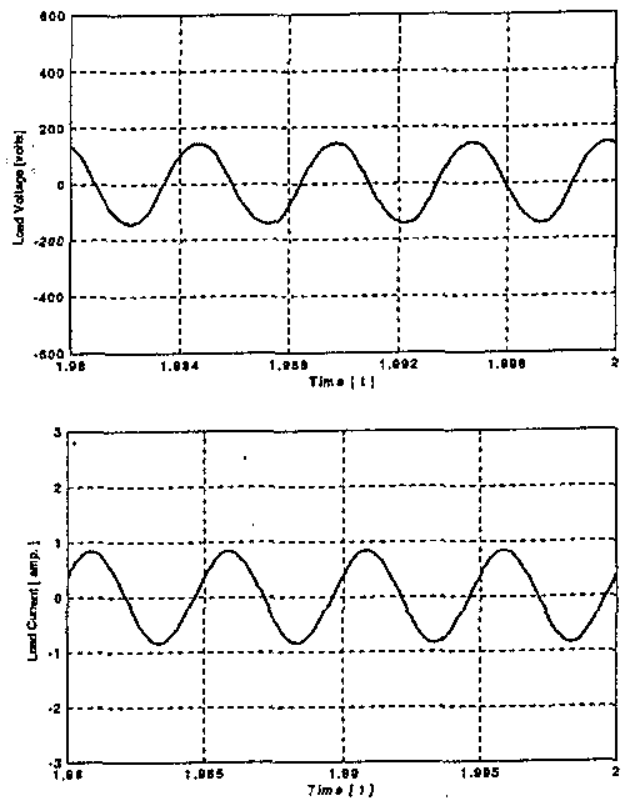

(a) Simulation results

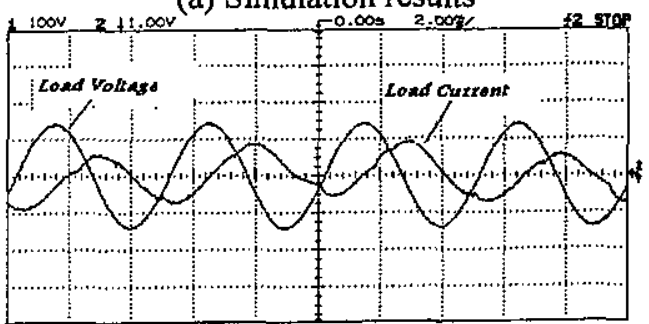

(b) Experimental results

Fig. 20 Simulation and Experimental results at $50 \%$ duty ratio.

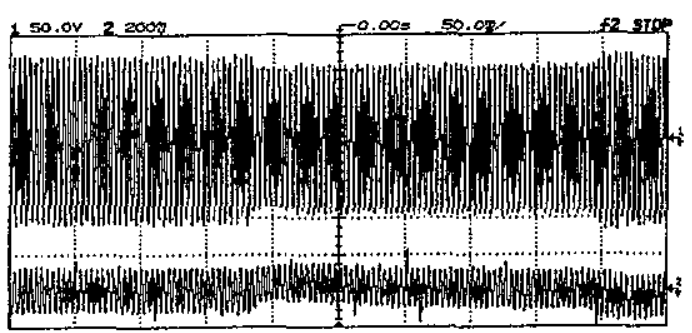

Fig. 21 The load voltage and current due to negative and positive change in reference voltage.

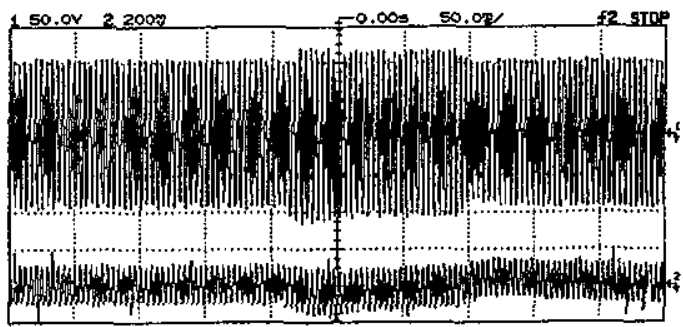

Fig. 22 The load voltage and current due to positive and negative change in reference voltage. 


\section{CONCLUSION}

A dc-ac single-phase voltage source inverter has been proposed and studied both theoretically and experimentally. The differential equations at different modes of operation are given to describe the system operation. Due to the nonlinearity, a linearized statespace model of the voltage source inverter is developed to study the effect of the system parameters, which affect the system stability using Root-locus analysis since the stability is the most important parameter to ensure the reliability of any system. A feedback output voltage control loop is given with PI controller to enhance the system stability and ensure that the constant load voltage is pure sinusoidal waveform irrespective of disturbances. Liapunov stability method is applied to determine the condition of the modulation index, for a stable system. The proposed system is designed and built in the laboratory to verify the simulation results. The results are found to be in a good agreement. The technique presented in this paper is applicable for any system with different parameters.

\section{REFERENCES}

[1] P.D Ziogas, "Optimum Voltage and Harmonic Control PWM Technique for Three-Phase Static UPS Inverters", IEEE Trans. Ind. Appli., vol. IA16, No. 4 pp. 542-546, July/Aug 1980.

[2] P.D Ziogas, S.Maias, and EP.Wiechman, "Applications of Current Source inverters in UPS System", IEEE Trans. Ind. Appli., vol. 25, No. 3 pp. 408-418, May/June 1989.
[3] Naser M. Abdel-Rahim, John E. Quaicoe "Analysis and Design of a Multiple Feedback Loop Control Strategy for Single-Phase Voltage Source UPS Inverters", IEEE Transactions on power electronics, vol. 11, No. 4 pp. 532-541, july 1996.

[4] Ramon O. Caceres, Ivo Barbi, "A Boost DC-AC Converter: Analysis, Design, and Experimentation", IEEE Transactions on power electronics, vol. 14 , No. 1 pp. 408-418, january1999.

[5] M. Orabi, T. Ninomiya "A Stability Assessment Tool For PFC Converter" EPE 2003- Toulouse.

[6] Emnianuel Godoy, Sihem Tebbani, Yann Louvain, Karl Sauterau "Stability Analysis of a Constant-Power Inverter", EPE 2003- Toulouse.

[7] Igor Y. Korotyeyev, Zbigniew Fedyczak "The $\mathrm{Dc} / \mathrm{Dc}$ Converter Stability- A Comparison of Analysis Methods", EPE 2003- Toulouse.

[8] S. Bregeon, A. Benchaib, S. Poullain, J. L. Thomas "Robust DC Bus Voltage Control Based on Backstepping and Liapunov Methods for Long Distance VSC Transmission Scheme", EPE 2003Toulouse.

[9] Marco Liserre, Remus Teodorescu, Frede Blaabjerg "Stability of Grid-Connected PV Inverters with Large Grid Impedance Variation", $35^{\text {th }}$ annual IEEE power electronics specialists conference, Aachen-Germany 2004, pp. 47734779.

\section{APPENDIX}

$R_{\mathrm{f}}=4 \Omega \quad L_{\mathrm{f}}=5 \mathrm{mH} \quad \mathrm{C}_{\mathrm{f}}=100 \mu \mathrm{F} \quad \mathrm{R}_{\mathrm{f}}=7 \Omega$

$\mathrm{L}_{\mathrm{l}}=7.14143 \mathrm{mH} \mathrm{V}_{\mathrm{dc}}=30 \mathrm{~V} \mathrm{~V}_{\mathrm{m}}=5 \mathrm{~V} \mathrm{~V}_{\mathrm{C}}=0 \rightarrow 5 \mathrm{~V}$ $\mathrm{f}_{\mathrm{s}}=200 \mathrm{~Hz} \quad \mathrm{~V}_{\mathrm{r}}=3.4 \mathrm{~V} \quad \mathrm{~K}_{\mathrm{P}}=0.1 \quad \mathrm{~K}_{\mathrm{I}}=0.01$ 